\title{
An Iterative and Incremental Approach for e-Learning Ontology Engineering
}

\author{
doi:10.3991/ijet.v4i1.696 \\ S. R. Heiyanthuduwage ${ }^{1}$, D. D. Karunaratna ${ }^{2}$ \\ ${ }^{1}$ Charles Sturt University Study Centre, Darlinghurst, Australia \\ ${ }^{2}$ University of Colombo School of Computing, Colombo, Sri Lanka
}

\begin{abstract}
There is a boost in the interest on ontology with the developments in Semantic Web technologies. Ontologies play a vital role in semantic web. Even though there is lot of work done on ontology, still a standard framework for ontology engineering has not been defined. Even though current ontology engineering methodologies are available they need improvements. The effort of our work is to integrate various methods, techniques, tools and etc to different stages of proposed ontology engineering life cycle to create a comprehensive framework for ontology engineering. Current methodologies discuss ontology engineering stages and collaborative environments with user collaboration. However, discussion on increasing effectiveness and correct inference has been given less attention. More over, these methodologies provide little discussion on usability of domain ontologies. We consider these aspects as more important in our work. Also, ontology engineering has been done for various domains and for various purposes. Our effort is to propose an iterative and incremental approach for ontology engineering especially for e-learning domain with the intention of achieving a higher usability and effectiveness of e-learning systems. This paper introduces different aspects of the proposed ontology engineering framework and evaluation of it.
\end{abstract}

Key words—ontology engineering, e-learning, methodology

\section{INTRODUCTION}

Interest in researchers on ontology engineering has increased in last few years. One of the main reasons for this is the rapid evolution of Semantic Web. Semantic Web can be seen as an extension of the current Web, aimed at augmenting the information with well-defined semantics, to enable computers and people to work in cooperation [1]. One of the prime objectives of the Semantic web is to define Web resources and the relationships between them at a conceptual level. In this task knowledge structures intended at the conceptual level such as ontologies play a major role.

There are several different definitions for ontology; according to Tom Gruber ontology is an explicit specification of the domain and the relationships between them [2]. Typically, ontologies are domain specific.

The objective of this paper is to propose an enhanced ontology-engineering framework to develop ontologies in the e-learning domain. One enhancement is the process we follow is illustrated as an ontology engineering process model (Annex: figure-1). The proposed process integrates several aspects and practices of ontology engineering. It is not practical to build an ontology in a single giant step, it has to be done in a set of phases. In this process, the ontology engineering happens in an iterative and incremental fashion seamlessly. Our approach is a step ahead to the current approaches, due to above features, and during teach phase and in iterations knowledge workers play a major role in collaboration of knowledge engineers. In addition to that we identify in what stages, who (knowledge engineer or the knowledge worker) need to contribute more for evaluation and what are their exact roles. Also, we try to integrate existing related techniques and tools to achieve synergy. Furthermore, we tune this approach to achieve higher usability and effectiveness, what are key attributes for success of any system. The utilization of proposed approach thus leads to an enhanced, customized and effective (e-learning) ontology that meets the end user's (learner) requirements.

The methodology we propose consists of five main stages and each stage consists of a set of activities. The rest of this paper is organized into several sections. The section II gives an overview of related research work and section III introduces the tools and techniques used in this framework. Section IV introduces the proposed framework, followed by section $\mathrm{V}$, which is on importance on iterative evaluation of ontology. Section VI provides an analysis of initial results and section VII is on future work and section VIII is the conclusion. Finally, references are given in section IX.

\section{RELATED WORK}

Most of the early research work on ontology development was aimed at several individual aspects of ontology engineering, such as ontology modelling, ontology design, ontology standards and ontology evolution. Whereas recent related research work has concentrated on ontology engineering, which integrates those individual aspects. For example, the emphasis of 'HCOME methodology' [3] is on getting more user involvement in the ontology development. 'Communitydriven ontology engineering' given in [5] uses wikis as a collaborative environment. Further more, 'Ontology maturing process' [4] is targeted at collaborative tagging systems. In addition to them, 'HCOME methodology' [3], Social Bookmarking and Lightweight Engineering of Ontologies (SOBOLEO) [4] propose some additional work done on ontology engineering methodologies. Also, most of them discuss the importance of involvement of knowledge workers (users) in ontology engineering, in addition to the knowledge engineer (ontology engineers).

In the history of the ontology engineering evolution, several generations can be identified, what we propose as first generation and second-generation ontology engineering methodologies. In 'first generation' ontology 
engineering methodologies, the ontology engineers alone did ontology engineering, with no participation of knowledge workers (users). However, 'second generation' of ontology engineering methodologies, gets more user involvement [3] and use of collaborative environments such as wikis [5] and collaborative tagging systems [4]. Another difference between first and second-generation ontology engineering methodologies is mainly stand-alone ontology engineering tools have been used in early methodologies; such tools include protégé and OIModeler, whereas in second generation ontology engineering methodologies, integrated tools have been used. Wikis can be considered as a one popular collaborative ontology engineering environment tool. Another example is collaborative tagging systems [4]. Integrating various tools today has enhanced even other tools such as protégé.

Also, when we consider the life cycle aspects of ontology engineering, in different approaches different life cycle phases are proposed. It is obvious, that has to happen, as this different work is done on different domains and with different objectives. 'Ontology maturing process' [4] gives a considerable coverage of ontology engineering, which consists of the four phases, emergence of ideas, consolidation in communities, formalization and axiomatization. These phases includes relevant activities to be done. However, it does not go into steps, what should be followed in each phase. When 'HCOME methodology' is considered, it defines three phases (specification, conceptualization and exploitation) and each of which is elaborated with tasks to be carried out [3]. Consensus building approach in ontology engineering proposed by Karapiperis [6] is based on the four phases proposed by Holsapple [7] in his collaborative approach for ontology engineering. A summary of ontology engineering approaches has been proposed in [8] includes the approaches, Johannesson's method, Kashap's method, Philip and clleagues' approach, Rubin ans colleagues approach, Stajanovic and colleagues approach, Saltz and colleagues approach, Spyns and colleagues' approach and the approach they propose Kedri's approach.

Comparable to software engineering, ontology engineering has only several different Computer Aided Software Engineering (CASE) Tools to support ontology engineering. They are of immense use to the ontology engineers. Some of those ontology-engineering tools have gained higher popularity and acceptance among the ontology engineers. For example Jena, Sesame, Protégé, KOAN, Jastor, and D2RQ [9]. These are also called as ontology management systems and they manipulate ontologies. A disadvantage of these tools is integration of them with other modeling or development tools is difficult [9]. One example for works done using protégé is [6] and they provide a list of tools in use with introductions. Also, new tools are been developed with different objectives; an example is Social Bookmarking and Lightweight Engineering of Ontologies (SOBOLEO) proposed in [4].

\section{INTEGRATING RELATED TOOLS AND TECHNIQUES WITH ONTOLOGY ENGINEERING}

Several different interrelated techniques can be used effectively in the process of ontology development. In this paper we shows techniques we see as most appropriate at each stage and the relationship between these techniques. At early stages of the process we utilize planning techniques, concept gathering techniques, concept modeling techniques, and planning support tools and concept modeling tools. In middle stages of the process we utilize different ontology design techniques such techniques are for ontology base design, user interface design, representation of ontology in different ontology languages such as RDF, OIL+DAML and OWL, mapping ontology specification into these ontology languages. In later stages design and implementation of inference rules and queries on ontology and mapping ontology into tree menus and other widgets in user interfaces.

Different techniques and activities of ontology engineering, mentioned above are supported by different ontology engineering tools; some call them as ontology management systems [9]. These tools can be incorporated with different stages. A summary of ontology management systems can be found in [9]. It includes the tools, Jena, Sesame, Protégé, KOAN, Jastor, and D2RQ. Some of these tools have become popular among the ontology engineering community. We used Protégé in our work.

Creation of the ontology layer, on top of data (database) layer, has several advantages, such as extracting the conceptual knowledge from technical details, domain knowledge becomes reusable, makes the system more user oriented than technical oriented.

\section{ITERATIVE AND INCREMENTAL ONTOLOGY ENGINEERING}

Our approach for ontology development comprises of five main stages namely,

1) Planning

2) Concept gathering and Ontology Conceptualization

3) Ontology design

4) Build Ontology

5) Ontology Usage and evolution

Most ontology engineering approaches propose and a sequence of stages with some iteration [19]. In this approach we stress several aspects of ontology engineering. They are first, iterative enhancement of ontology in all stages starting from conceptualization phase, designs, building and usage of ontology. Secondly, we gradual construct the ontology, from bits and pieaces through the stages given above to get the final operational ontology. Thirdly, obtaining continuous involvement of knowledge workers (learners) for the influx of ideas, suggestions and for iterative evaluation of intermediate products of ontology engineering process. Fourthly, the proposed ontology-engineering framework consists of five main stages (table 1) and we have listed associated activities and techniques for each stage of ontology engineering. Fifthly, we pay careful attention and follow guidelines to achieve higher usability of the ontology. We call this a framework as we encapsulate a list of good practices into ontology engineering.

The stage of this proposed approach with associated activities and deliverables are depicted in a diagram (figure 1) and they are briefly introduced below. 
TABLE I.

SUMMARY OF ONTOLOGY ENGINEERING STAGES

\begin{tabular}{|c|c|c|c|}
\hline Main Phase & Activity & Evaluation and Iteration & Techniques \\
\hline Planning & $\begin{array}{l}\text { Define schedule for ontology engineering, scope, } \\
\text { constraints, stakeholders, sources }\end{array}$ & Hold an internal review & $\begin{array}{l}\text { Gantt charts } \\
\text { Evaluation Plan }\end{array}$ \\
\hline $\begin{array}{l}\text { Concept } \\
\text { gathering } \\
\text { and } \\
\text { Ontology } \\
\text { Conceptualiz } \\
\text { ation }\end{array}$ & $\begin{array}{l}\text { Collect reverent materials } \\
\text { Study existing systems } \\
\text { Meet stakeholders } \\
\text { Prepare concepts list } \\
\text { Identify concepts, relationships, properties and } \\
\text { constraints } \\
\text { Build concept model } \\
\text { Associate Metadata with ontology } \\
\text { Match ontology and metadata with user profiles } \\
\end{array}$ & $\begin{array}{l}\text { Distribute questionnaires } \\
\text { Hold an external review } \\
\text { Distribute questionnaires } \\
\text { Hold internal review and } \\
\text { external review }\end{array}$ & $\begin{array}{l}\text { Ontology Evaluation } \\
\text { (Questionnaires } \\
\text { Reviews) } \\
\text { Informal Discussions } \\
\text { Concept modeling } \\
\text { SCORM metadata } \\
\text { User profiles \& preferences }\end{array}$ \\
\hline $\begin{array}{l}\text { Ontology } \\
\text { design }\end{array}$ & $\begin{array}{l}\text { Ontology architectural design, } \\
\text { Map conceptual model into ontology base, } \\
\text { Axiomatization, } \\
\text { Define inference rules, } \\
\text { Define ontology queries }\end{array}$ & $\begin{array}{l}\text { Distribute questionnaires } \\
\text { Hold internal review and } \\
\text { external review }\end{array}$ & $\begin{array}{l}\text { Lexon definition } \\
\text { Ontology base design } \\
\text { DL, FOL } \\
\text { Ontology Evaluation for } \\
\text { taxonomic errors and design } \\
\text { anomalies }\end{array}$ \\
\hline $\begin{array}{l}\text { Build } \\
\text { Ontology }\end{array}$ & $\begin{array}{l}\text { Build database or Map ontology into } \\
\text { (XML/RDF/OWL), } \\
\text { Create user interfaces with ontology components, } \\
\text { Implement inference rules on ontology, } \\
\text { Implement ontology queries }\end{array}$ & $\begin{array}{l}\text { Internal review } \\
\text { Distribute questionnaires on } \\
\text { user interfaces } \\
\text { Distribute questionnaires on } \\
\text { query results }\end{array}$ & $\begin{array}{l}\text { Ontology base, Relational data } \\
\text { modeling } \\
\text { XML, RDF, OWL } \\
\text { User Interface design } \\
\text { Techniques, GUI Techniques } \\
\text { SPARQL, Ontology Evaluation }\end{array}$ \\
\hline $\begin{array}{l}\text { Ontology } \\
\text { Usage and } \\
\text { evolution }\end{array}$ & $\begin{array}{l}\text { Make ontology accessible to learners, } \\
\text { Gather learner feedback and change requests. }\end{array}$ & $\begin{array}{l}\text { Questionnaires on problems } \\
\text { encountered, } \\
\text { Questionnaires on an change } \\
\text { requests }\end{array}$ & $\begin{array}{l}\text { LMS } \\
\text { Ontology Evaluation }\end{array}$ \\
\hline
\end{tabular}

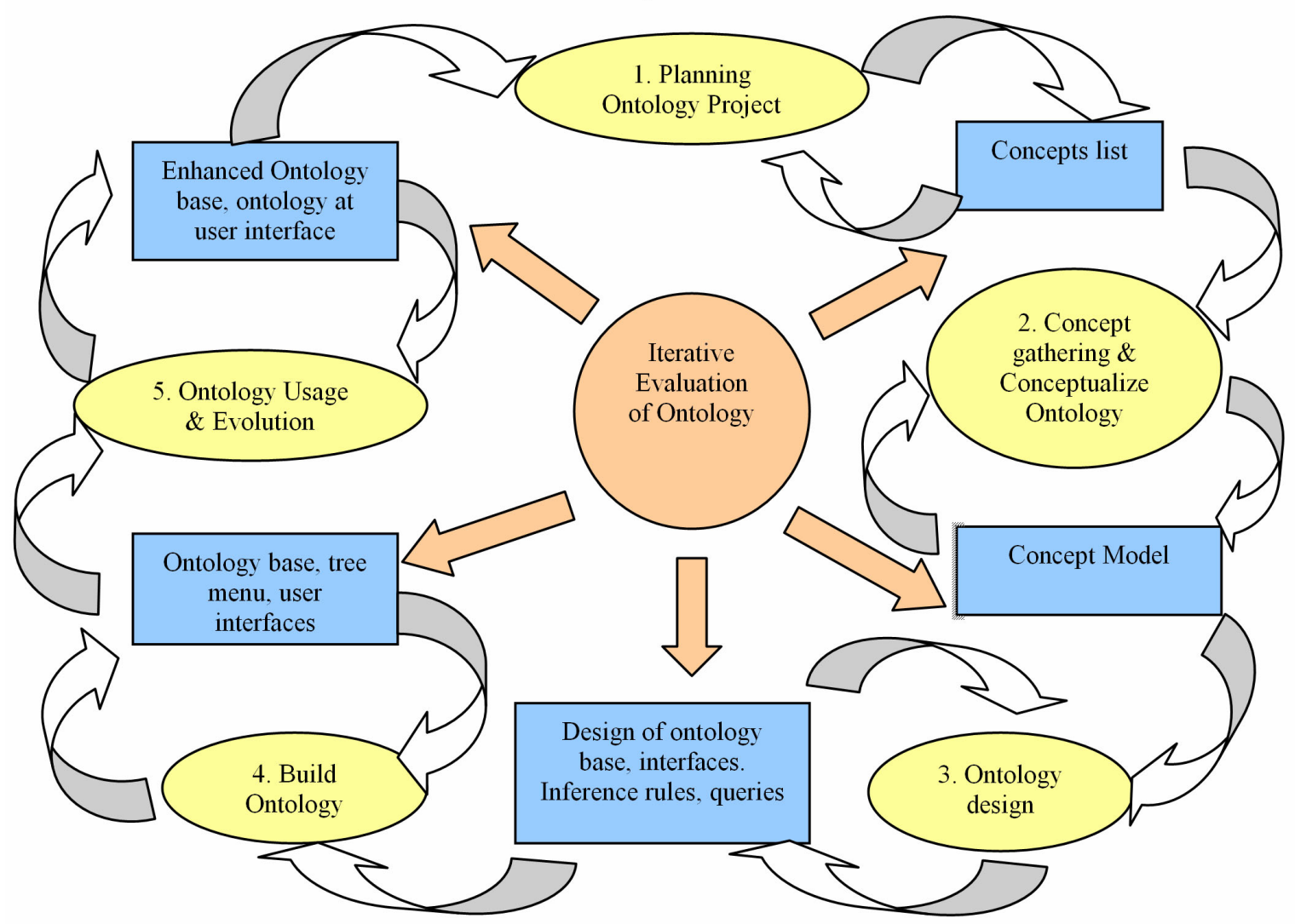

Figure 1. Proposed Iterative \& Incremental Ontology Engineering Methodology 


\section{A. Planning}

Like any other software projects the ontology development also needs careful planning. Also the scope of the ontology is specified excluding the irrelevant areas of the domain. Also, the resources to gather concepts and their definitions are identified and listed. Also, the stakeholders including the knowledge engineers and knowledge workers, whose participation and feedback are important, are identified. Moreover knowledge engineers need to identify any constraints on activities and any remedial actions need to be taken against them are ear marked. Another important activity to be carried out is identification of time milestones for the completion of each stage and iterative evaluation.

The scope of our ontology research is the e-Learning domain. However, due to the wider scope of e-Learning domain, we do our research considering the learning management system (LMS) of Bachelor of Information Technology (BIT) degree programme of University of Colombo School of Computing (UCSC) / www.bit.lk. The main stakeholders of this LMS are the programme coordinator of UCSC BIT, content developers, students registered with UCSC for BIT and studying at accredited centers (we call them as learners) and ontology engineers.

\section{B. Concept Gathering and Ontology Conceptualization}

To build the domain ontology, we need to know, concepts, relationships between concepts, properties of them and constraints on concepts, which are the basic elements of ontology. First we need to identify the concepts. For this, we need to know what resources to be used find those concepts. Mostly different documents (may be in current systems) and knowledge workers become the resources for knowledge engineers.

In the e-learning domain of consideration, we identified various course materials and knowledge workers (content developers and learners as resources (table 2).

TABLE II.

RESOURCES FOR CONCEPT GATHERING AND AVAILABILITY

\begin{tabular}{|l|l|l|}
\hline No & \multicolumn{1}{|c|}{ Resource } & \multicolumn{1}{c|}{ Availability } \\
\hline 1 & Study Materials & http://www.bit.lk web site \\
\hline 2 & $\begin{array}{l}\text { BIT programme } \\
\text { coordinator }\end{array}$ & BIT Office, Colombo-7 \\
\hline 3 & $\begin{array}{l}\text { Examiners and } \\
\text { curriculum developers }\end{array}$ & $\begin{array}{l}\text { At UCSC, other Universities, } \\
\text { individuals from the industry }\end{array}$ \\
\hline 4 & Content developers & At UCSC \\
\hline 5 & Course coordinators & At centers, spread island wide \\
\hline 6 & $\begin{array}{l}\text { Learners (UCSC BIT } \\
\text { Students) }\end{array}$ & $\begin{array}{l}\text { Registered at BIT office and } \\
\text { studying at different teaching } \\
\text { centers }\end{array}$ \\
\hline
\end{tabular}

We identified a set of relevant concepts from the above resources. Meanings of such ontology concepts are defined to avoid any inconsistencies and misinterpretations. Such definitions are found in linguistic resources such as dictionaries, thesaurus, glossaries and lexicons. Even electronic resources are available, for example wikipedia (http://www.wikipedia.com) and wordnet (www.wordNet.com).

Based on the information gathered (concepts), ontology is conceptualized in this stage, using a concept map [10]. Even though ontology is not hierarchical, we arrange the concepts in a hierarchy to make accessing concepts easy. A concept map shows a concept as a node and a relationship as an arch (edge) and each relationship are annotated with semantics. Here we use class diagrams as concept maps to model the domain.

The e-learning ontology we propose is built as a collection of modules to increase the reusability, maintenance and to customize each module to achieve the expected usability features. These modules are arranged in a hierarchy. The top module of e-learning domain ontology module is given below (figure 2) as a class diagram.

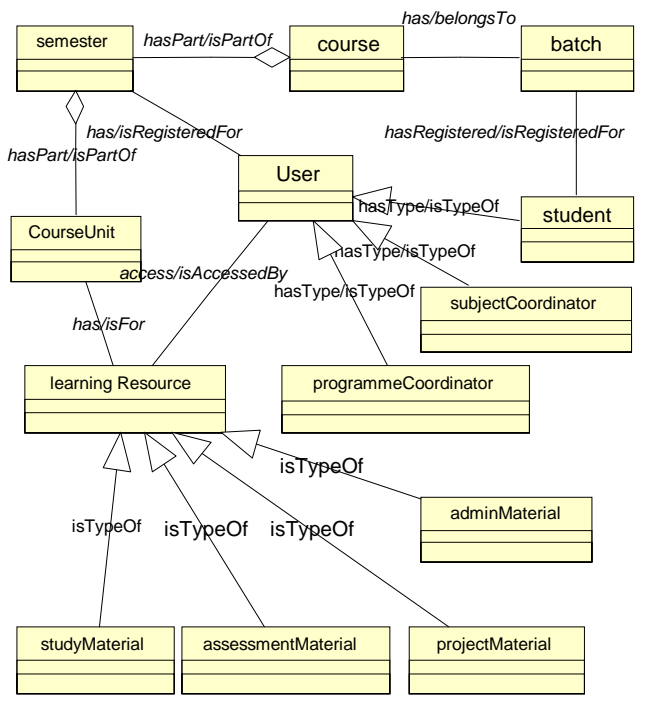

Figure 2. The top module of e-learning ontology

A set of lower level modules has been identified associated to the top module. One of them is the study materials module (figure 3 ).

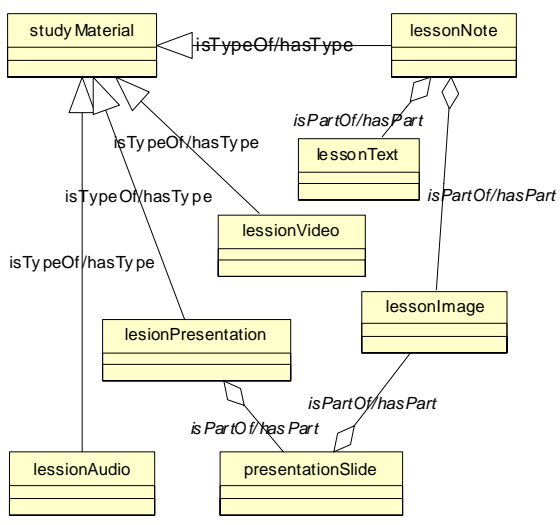

Figure 3. Study material module of e-learning ontology

We selected the object-oriented tool Rational Rose as modeling tool. Even the W3C has recommended ontology language OWL is based on object-oriented approach.

\section{Ontology design}

Ontology can be designed in several ways. One such way is to design ontology as an ontology base. Here we map the concepts and relationships in concept map into lexons and then into ontology base. An ontology base can be viewed as a collection of domain axiomizations. Such axiomizations consist of binary conceptual relationships, 
which are called as lexons. A lexon is given in the format $<\gamma$ : Term1, Role, InvRole, Term2>. In this $\gamma$ is called as the context identifier, Term 1 and Term2 are linguistic terms, which represents concepts. Role and InvRole is the role pair of the binary relationship [11].

A lexon is defined as a tuple in the format of $\langle\gamma$ : T1, $r$, $r^{\prime}$, T2>. According to this definition, $\gamma$ is the context identifier, T1 and T2 are linguistic terms and $r$ and $r^{\prime}$ is a pair of roles of a binary relationship. Also, each concept can be defined as $(\gamma, T) \rightarrow C$ [11], which means a concept within a specific domain needs to be unique. In this research the domain identifier is e-Learning. Therefore concepts defined within the e-learning domain are unique.

A set of terms and the binary relationships (lexons) between them of the e-learning domain can be given as follows,

<e-Learning: Course, Has-Part, Is-Part-Of, Semester> $<$ e-Learning: Semester, Offers, Is-Offered-In, Subject $>$ $<$ e-Learning: Subject, Has, Is-Of, Handout>

<e-Learning: Course, Is-Supported-By, Supports, Resource-Person>

<e-Learning: Resource-Person, Has-Type, Is-Type-Of, Lecturer> 3).

These lexons can be mapped in to ontology base (table

An ontology base developed for a specific domain consists of lexons related to that domain. However, it is application independent. Therefore different lexons in an ontology base can be utilized by different application to satisfy different user requirements. For this the application we use axioms and inference rules defined on ontology. That means, lexons in an ontology base are extracted by the application considering the purpose to achieve usability.

Upper Ontologies are formal axiomatic systems that describe the most general categories of reality. Such ontologies are not only application and task independent but also domain (and possibly language) independent axiomatizations.

Another activity we perform in this stage is to define inference on ontology. Inference is the process (or act) of deriving a conclusion based solely on what one already knows (wikipedia). Inference needs to be done on ontology to provide information on concepts, with the help of relationships between ontology, properties of concepts and constraints on them, defined in the ontology. In this research we use inference rules defined in FOL. To increase reasoning power using inference rules of FOL, each lexon in e-learning ontology base is mapped into three statements of first order logic [12] as shown below.

$$
\begin{aligned}
& \forall_{\mathrm{x}} \mathrm{T}_{1}(\mathrm{x}) \rightarrow\left(\forall_{\mathrm{y}} \mathrm{r}(\mathrm{x}, \mathrm{y}) \rightarrow \mathrm{T}_{1}(\mathrm{y})\right) \\
& \forall_{\mathrm{y}} \mathrm{T}_{2}(\mathrm{y}) \rightarrow\left(\forall_{\mathrm{x}} \mathrm{r}(\mathrm{y}, \mathrm{x}) \rightarrow \mathrm{T}_{2}(\mathrm{x})\right) \\
& \forall_{\mathrm{x}, \mathrm{y}} \mathrm{r}(\mathrm{x}, \mathrm{y}) \leftrightarrow \mathrm{r}^{\prime}(\mathrm{y}, \mathrm{x}) \\
& \forall_{\mathrm{x}} \text { Semester }(\mathrm{x}) \rightarrow\left(\forall_{\mathrm{y}} \text { Offers }(\mathrm{x}, \mathrm{y}) \rightarrow \text { Subject }(\mathrm{y})\right) \\
& \forall_{\mathrm{y}} \text { Subject }(\mathrm{y}) \rightarrow\left(\forall_{\mathrm{x}} \text { is-Offered-In(y,x) } \rightarrow \text { Semester }(\mathrm{x})\right) \\
& \forall_{\mathrm{x}, \mathrm{y}} \text { Offers }(\mathrm{x}, \mathrm{y}) \leftrightarrow \text { Is-Offered-In(y,x) }
\end{aligned}
$$

To satisfy user's information requirements we can create queries using an ontology query language.
TABLE III.

LEXONS OF AN E-LEARNING DOMAIN

\begin{tabular}{|c|c|c|c|c|}
\hline Context & Term1 & Role & InvRole & Term2 \\
\hline e-Learning & Course & Has-Part & $\begin{array}{c}\text { Is-Part- } \\
\text { Of }\end{array}$ & Semester \\
\hline e-Learning & Subject & Has & Is-Of & Note \\
\hline e-Learning & Course & $\begin{array}{c}\text { Is- } \\
\text { In }\end{array}$ & Subject \\
By & Offers- & Supports & $\begin{array}{c}\text { Resource- } \\
\text { Person }\end{array}$ \\
\hline e-Learning & $\begin{array}{c}\text { Resource } \\
\text {-Person }\end{array}$ & $\begin{array}{c}\text { Has-Type } \\
\text { Is-Type- } \\
\text { Of }\end{array}$ & Lecturer \\
\hline
\end{tabular}

\section{Build Ontology}

In this phase the ontology designed in previous stage is mapped into an implementation. Mapping the ontology designed is done in to several layers. One layer is an ontology base. That is the ontology base is created according to relational database concepts. In this process database tables are created for concepts, sub concepts, metadata, similar idea is proposed in [13]. Another layer of mapping of ontology is user interface with what the users can interact. Also, for the purpose of exchange of ontology and machine understandability of ontology it is mapped into a semantic web language or an ontology language such as XML, RDF and OWL. This makes the ontology transmittable over a network to distance application or a learner.

The implementation of the ontology in user interface for the interaction of the users is done here in several levels of user interfaces. First at the highest level, a tree menu represents the ontology, which consists of all concepts at high level and their relationships. Then at the next level, each concept is elaborated with roles, role restrictions, other links and etc to elaborate the concepts.

Inference rules and query interfaces are implemented at application level. Inference rules and queries are included within application programs. When users make requests through the user interfaces or from the domain ontology at user interface inference rules and queries are executed.

\section{E. Ontology Usage and Evolution}

In this stage the ontology is put into operational use of the users and any mistake in representation of the ontology, omissions and alterations to concepts, relationships, properties and constraints are identified by the user and given as a feedback to the ontology engineer and any changes to the ontology knowledge workers. Feedback of learners (knowledge workers) is obtained using questionnaires and change request forms. Based on this feedback and changes proposed, the ontology engineer amends the ontology to get at a higher usable and effective ontology for e-learning. With this work the final ontology product get evaluated. It is a summative evaluation activity. Evolution of the ontology continues iteratively to the future with the operational use of it.

\section{ITERATIVE EVALUATION OF ONTOLOGY}

In addition to the evaluation of final ontology product (summative evaluation) as discussed above, we apply iterative evaluation of intermediate ontology products 
(formative evaluation) of each stage by means of iterative evaluation. This evaluation process pays a special attention for usability of ontology [20]. Due to the importance of it, as given in our framework (Annex: figure-1), we have provide a separate discussion on it.

In our work, the e-learning knowledge workers are content developers and learners. The e-learning ontology is especially developed for the knowledge workers. Obtaining their acceptance of the e-learning ontology is an important factor in all our work. It is not an easy task. However, it can be supported by different techniques. One-way of achieving this is to evaluate the ontology by the knowledge engineers [21] before make it accessible to the knowledge workers. However, the best way of doing this is to get the learner involvement [22] from the out set of the ontology engineering and keep the continued participation of them till the whole work is over. So it becomes formative evaluation of the ontology. When the involvement of the knowledge engineers and the knowledge workers are obtained, it becomes a collaborative evaluation approach. A collaborative approach makes a blend of knowledge workers experience on domain and knowledge engineers technical knowledge for achieving a higher usability and subsequently higher acceptance of the ontology with higher accuracy of representation.

First, the product of phase two, the initial list of concepts, was evaluated by using questionnaires and reviews. Also, the products of other stages are evaluated using questionnaires and reviews. This helps to identify any improvements at an early stage and to make them at a low effort and cost.

\section{A. Evaluation by Questionnaires and Reviews}

Usability of an information system can be evaluated in three main methods. They are testing, inspection and inquiry. Each of these broad categories includes several methods. In our work we evaluate the usability of elearning ontology we develop by using two main evaluation methods what come under inquiry. They are questionnaires [14] and focus groups (reviews) [15]. However, in general, in addition to the above to evaluate an ontology, interviews, feedback forms, discussion forums and also wikis [5] are used. In our approach we mainly used questionnaires and reviews. We get feedback from large numbers of stakeholders (knowledge workers) by using questionnaires and reviews are conducted using small groups of knowledge workers and knowledge engineers.

\section{ANALYSIS OF RESULTS}

Here we provide a partial analysis of iterative evaluation (formative evaluation) of ontology, what was done in the second phase of the proposed framework. We distributed questionnaires including some questions to identify the need for ontology and concepts of the domain. These questionnaires were distributed among content developers and learners. We could collect completed questionnaires from ten content developers and thirty learners. In this initial questionnaire we included the question: "Do you think that if a learner sees all terms/concepts of a course and semantic relationships between them in a user interface will make learning easy?" We included the responses "Yes" and "No". Our intention of including this question was to identify the need of developing an ontology for this system. The results we got are as follows (Table 4). For the above question twenty-seven learners has give the response "Yes", which is ninety percent and three learners has given the response "No", which is only ten percent. Seven content developers + programme coordinator has given the response "Yes", which comes to 63.6 percent and four content developers has given the response "only relevant terms", which comes to 36.4 percent and none of them has given the response "No". By this we can conclude that this clearly shows the need of an ontology for this e-learning system.

TABLE IV.

ANALYSIS OF RESPONSES

\begin{tabular}{|c|c|c|c|c|}
\hline Stake holders & Yes & $\begin{array}{c}\text { Percentage } \\
(\%)\end{array}$ & No & $\begin{array}{c}\text { Percentage } \\
(\%)\end{array}$ \\
\hline Learners & 27 & 90 & 3 & 10 \\
\hline $\begin{array}{l}\text { Content } \\
\text { Developers } \quad+ \\
\text { Programme } \\
\text { Coordinator }\end{array}$ & $\begin{array}{l}7 \\
(4)\end{array}$ & $\begin{array}{l}63.6 \\
(36.4 \quad \text { only } \\
\text { relevant } \\
\text { terms) }\end{array}$ & 0 & 0 \\
\hline Total & 34 & 82.9 & 3 & 0.7 \\
\hline
\end{tabular}

Also, the questionnaire included the relevance marking (high/ moderate/ low) for the terms (concepts). By this could identify most relevant concepts for this e-learning domain. It was noticed that only one workshop is done for the students to prepare them for project work. So, the system does not include concepts such as presentation guides and marking them. Only the final student thesis of this program is marked. Some stakeholders have mentioned the importance of some concepts such as discussion forums, feedback forms, and e-books.

\section{FUTURE WORK}

In the next round of evaluation, we have planned to evaluate the ontology design. For this we expect get higher participation of ontology engineers for expert evaluation and learner involvement for formative evaluation. In our work expert evaluation focuses more on taxonomic and design anomalies [23] of the e-learning ontology.

\section{VIII.CONCLUSION}

The objective of this paper is to see whether incremental development and iterative evaluation approach of ontology engineering leads to enhance and refine ontologies and provide higher usability for the knowledge workers. Also, we have proposed to achieve synergy of ontology engineering tools and techniques, by integrating them to different stages of the proposed framework. We are in the process of testing this framework by applying it to the e-learning domain and the results we obtained up to now are encouraging and initial results are summarized above. As future work we continue to other stages of the proposed methodology and evaluate deliverables (the ontology and related products) with learner participation. Hence, we propose and will further establish that proposed ontology engineering framework with iterative evaluation, involvement of knowledge workers and synergy of ontology engineering tools and techniques leads to continued refinement of the ontology and to get an enhanced ontology with higher usability. 


\section{REFERENCES}

[1] Berners-Lee T, Hendler J and Lassila (2001), The Semantic Web, Scientific American, vol. 284, no.5, may 2001, pp. 34-43.

[2] Noy N.F. and McGuiness D.L. (2001) Ontology Development 101: A Guide to Create Your First Ontology, Stanford Knowledge Systems Laboratory Technical Report KSL-01-05 and Stanford Medical Informatics Technical Report SMI-2001-0880, March 2001

[3] Kotis K, Vouros G.A, (200) "human-centered ontology engineering: the HCOME methodology”,

[4] Braun S, Schmidt A. Walter A. (200), Ontology Maturing: a Collaborative Web 2.0 Approach to Ontology Engineering

[5] Guy M., Bachlechner, Siorpaes (2006), OntoWiki: communitydriven ontology engineering and ontology usage based on Wikis. In WikiSym 2006: Proceedings of the 2006 international symposium on Wikis, pages 143-144, New York, NY, USA, 2006, ACM Press

[6] Karapiperis S, Apostolou D, (2006) Consensus Building in Collaborative Ontology Engineering Process, Journal of Universal Knowledge Management, Vol 1, no 3, (2006), 199-216

[7] Holsapple, 2002

[8] Gottgtroy P, Kasabov N, Macdonell S. (200), An Ontology Engineering Approach for Knowledge Discovery from Data in Evolving Domains,

[9] Pan Yue, etl (2005), An MDA-Based Sytem for Ontology Engineering, IBM Research Report, RC23795 (W0511-088) November 11, 2005, Computer Science

[10] Sowa J.F. (2006) 'Concept Mapping', AERA Conference, San Francisco, 10th April 2006 Available: http://www.jfsowa.com/tal ks/cmapping.pdf

[11] Jarrar, M (2006), 'Towards the notion of gloss, and the adoption of linguistic resources in formal ontology engineering'. Proceedings of the 15th International World Wide Web Conference, WWW2006. Edinburgh, Scotland. May 2006, ACM, 2006.

[12] Spyns P. etl, (2002), SIGMOD Record 31(4): 12-17. ISSN: 01635808. March 2002

[13] Falquet G, Jiang C.L.M., (200) A Framework to Specify Hypertext Interfaces for Ontology Engineering,

[14] Luwis J.R. (1995) IBM Computer Usability Satisfaction Questionnaires: Psychometric Evaluation and Instruction for Use, International Journal of Human-Computer Interaction, 7:1, 57-78

[15] Nielson J. (1993) Usability Engineering, pp. 214-216, Academic Press, 1993
[16] Denaux R, Dimitrova V, Aroyo L. (200), Interactive OntologyBased User Modelling for Personalized Learning Content Management,

[17] Lei Y., Motta E., Domingue J. (200), An Ontology-driven Approach to Web Site Generation and Maintenance,

[18] Salim K. Semy, Kevin N. Hetherington- Young, Steven E. Frey (200), Ontology Engineering: An Application Perspective,

[19] Fernandez-Lopez M. and Gomez-Pemez A. (2002) Overview and Analysis of Methodologies for Building Ontologies. Knowledge Engineering Review, 17(2):129-156 (doi:10.1017/S026988890 2000462)

[20] Deborah Hix, Joseph L. Gabbard, J.Edward Swan H, Mark A. Livingston, Tobias H. Hollerer, Simon J. Julier, Johan Baillot, Dennis Brown, (2004), A Cost-Effective Usability Evaluation Progression for Novel Interactive Systems, Proceedings of the Hawaii International Conference on System Sciences (HICSS-37), January 2004

[21] Andriana Granic, Vlado Glavinic, Slavomir Stankov, (2004), Usability Evaluation Methodology for Web-based Educational Systems, 8th ERCIM Workshop "User Interfaces For All", 28-29 June 2004, Available: http://www.ui4all.gr/workshop2004/files /ui4all_proceedings/adjunct/evaluation/28.pdf

[22] Cooper M. Colwell C. Jelfs A. (2007), Embedding accessibility and usability: considerations for e-learning research and development projects, ALT-J, 15:3, 231-245 (doi:10.1080/0968 7760701673659)

[23] Muhammad Fahad, Muhammad Abdul Qadir, (2008), A Framework for Ontology Evaluation, ICCS Supplement 2008: 149-158. 12, Available: http://ftp.informatik.rwthaachen.de/Publications/CEUR-WS/Vol-354/p59r.pdf

\section{AUTHORS}

S. R. Heiyanthuduwage (rohithaidm@yahoo.co.uk, SHeiyanthuduwage@studygroup.com) is with the Charles Sturt University Study Centre, Study Group Australia, 63, Oxford Street, Darlinghurst, NSW 2010, Australia. +94112-554992/3.

D. D. Karunaratna (ddk@ucsc.cmb.ac.lk) is with the University of Colombo School of Computing, 35, Reid Avenue, Colombo 7, Sri Lanka. +94-112-591245.

Manuscript received 15 October 2008. Published as submitted by the authors. 